\title{
Commentary
}

Juan Francisco Peña-Cardelles*, José Ernesto Moro-Rodríguez, José Luís Cebrián-Carretero, José Juan Pozo-Kreilinger

\section{Commentary on "Clinicopathological features of programmed cell death-ligand 1 expression in patients with oral squamous cell carcinoma"}

https://doi.org/10.1515/med-2022-0431

received November 3, 2021; accepted January 14, 2022

The clinical and pathological value of programmed cell death-ligand 1 (PD-L1) expression in the oral squamous cell carcinoma (OSCC) has originated the research of different studies that try to determine the real relationship between this disease and this immune checkpoint since the latest clinical trials have related possible improvements in the blockade of this immune checkpoint through immunotherapy.

Is for that reason that new systematic reviews have tried to explain this relationship. Cui and $\mathrm{Su}(2020)$ in the review and meta-analysis "Clinicopathological features of programmed cell death-ligand 1 expression in patients with oral squamous cell carcinoma" aimed to clarify the role of PD-L1 in OSCC [1]. For that, they included a large sample of 1,947 participants from a total of 15 studies.

The authors found very interesting results concerning PD-L1 and its correlation with sex, stages, and human papillomavirus (HPV) infection status, although they have described that there is a controversy between the included

\footnotetext{
* Corresponding author: Juan Francisco Peña-Cardelles, Oral surgery and Implantology Department, Universidad Rey Juan Carlos, Faculty of Health Sciences, University Clinic, Av. de Atenas, S/N, 28922 Alcorcón, Madrid, Spain; Oral and Maxillofacial Surgery Division and Prosthodontics Division, School of Dental Medicine, University of Connecticut, Connecticut, United States, e-mail: juanfranciscopenacardelles@gmail.com José Ernesto Moro-Rodríguez: Universidad Rey Juan Carlos, Madrid, Spain

José Luís Cebrián-Carretero: Oral and Maxillofacial Surgery Department, Hospital Universitario La Paz, Madrid, Spain José Juan Pozo-Kreilinger: Department of Pathology, Universidad Autónoma de Madrid, Madrid, Spain; Department of Pathology, Hospital Universitario La Paz, Madrid, Spain
}

studies. However, the results concluded in this study may be confusing due to the large sample size of the studies included in this systematic review and meta-analysis.

The authors have used as inclusion criteria only OSCC patients confirmed by histology. However, from the total of 15 studies included, 6 studies (De Meulenaere et al., 2017; Kim et al., 2016; Sato et al., 2019, Upko et al., 2013, Hong et al, 2016; Hong et al., 2019) [2-8] were research carried out exclusively on patients with oropharyngeal squamous cell carcinoma (OPSCC) and another study (Ock et al., 2016) [9] included both oropharyngeal and non-oropharyngeal carcinoma. Therefore, approximately 915 patients of the total 1,947 are OPSCC patients and not OSCC.

Nowadays, it is established that OPSCC is different in comparison with OSCC, since the diagnostic, the clinical behaviour, the treatment, and the prognostic are very different, a fact that has already been described in the TNM classification [10]. Besides, this bias has already been found in other systematic reviews in this field [11].

On the other hand, the authors have found a strong relationship between the HPV prevalence and OSCC, obtaining important conclusions concerning the HPV status and the PD-L1 in OSCC. Nevertheless, almost the total sample where the HPV was studied was compounded by OPSCC studies, since other studies have demonstrated the highest prevalence in OPSCC [12], while in the OSCC it is almost not prevalent [13], which is not consistent with the data and outcomes obtained with respect to the HPV status in the $\mathrm{Cu}$ and $\mathrm{Su}$ meta-analysis.

Due to the above-mentioned, we consider that it must have a caution interpretation to OSCC concerning the outcomes obtained by $\mathrm{Cu}$ and $\mathrm{Su}$ since almost half of the sample are OPSCC participants.

Funding information: Funding was not necessary in this article.

Conflict of interest: No conflicts of interest are declared. 
Data availability statement: Data sharing is not applicable to this article as no datasets were generated or analysed during the current study.

\section{References}

[1] Cui YX, Su XS. Clinicopathological features of programmed cell death-ligand 1 expression in patients with oral squamous cell carcinoma. Open Med (Wars). $2020 \mathrm{Apr}$ 17;15:292-301.

[2] De Meulenaere A, Vermassen T, Aspeslagh S, Deron P, Duprez F, Laukens D, et al. Tumor PD-L1 status and CD8(+) tumor-infiltrating $T$ cells: markers of improved prognosis in oropharyngeal cancer. Oncotarget. 2017;8(46):80443-52.

[3] Kim HS, Lee JY, Lim SH, Park K, Sun JM, Ko YH, et al. Association between PD-L1 and HPV status and the prognostic value of PD-L1 in oropharyngeal squamous cell carcinoma. Cancer Res Treat. 2016 Apr;48(2):527-36.

[4] Sato F, Ono T, Kawahara A, Kawaguchi T, Tanaka H, Shimamatsu K, et al. Prognostic impact of p16 and PD-L1 expression in patients with oropharyngeal squamous cell carcinoma receiving a definitive treatment. J Clin Pathol. 2019 Aug;72(8):542-9.

[5] Ukpo OC, Thorstad WL, Lewis JS Jr. B7-H1 expression model for immune evasion in human papillomavirus-related oropharyngeal squamous cell carcinoma. Head Neck Pathol. 2013;7(2):113-21.

[6] Hong AM, Vilain RE, Romanes S, Yang J, Smith E, Jones D, et al. PD-L1 expression in tonsillar cancer is associated with human papillomavirus positivity and improved survival: implications for anti-PD1 clinical trials. Oncotarget. 2016 Nov 22; 7(47):77010-20.

[7] Hong AM, Ferguson P, Dodds T, Jones D, Li M, Yang J, et al. Significant association of PD-L1 expression with human papillomavirus positivity and its prognostic impact in oropharyngeal cancer. Oral Oncol. 2019 May;92:33-9.

[8] Ock CY, Kim S, Keam B, Kim M, Kim TM, Kim JH, et al. PD-L1 expression is associated with epithelial-mesenchymal transition in head and neck squamous cell carcinoma. Oncotarget. 2016 Mar 29;7(13):15901-14.

[9] Amin MB, Greene FL, Edge SB, Compton CC, Gershenwald JE, Brookland RK, et al. The Eighth Edition AJCC Cancer Staging Manual: Continuing to build a bridge from a population-based to a more "personalized" approach to cancer staging. CA Cancer J Clin. 2017 Mar;67(2):93-9.

[10] Peña-Cardelles JF, Moro-Rodríguez JE, Cebrián-Carretero JL, Pozo-Kreilinger JJ. Commentary on 'Relationship of programmed death ligand-1 expression with clinicopathological features and prognosis in patients with oral squamous cell carcinoma: a meta-analysis' (He et al. Archives Oral Biol. 2020;114:104717). Arch Oral Biol. 2021 Oct 8;132:105274.

[11] Haeggblom L, Ramqvist T, Tommasino M, Dalianis T, Näsman A. Time to change perspectives on HPV in oropharyngeal cancer. A systematic review of HPV prevalence per oropharyngeal sub-site the last 3 years. Papillomavirus Res. 2017 Dec;4:1-11.

[12] Lingen MW, Xiao W, Schmitt A, Jiang B, Pickard R, Kreinbrink $P$, et al. Low etiologic fraction for high-risk human papillomavirus in oral cavity squamous cell carcinomas. Oral Oncol. 2013 Jan;49(1):1-8.

[13] Smitha T, Mohan CV, Hemavathy S. Prevalence of human papillomavirus16 DNA and p16INK4a protein in oral squamous cell carcinoma: a systematic review and meta-analysis. J Oral Maxillofac Pathol. 2017 Jan-Apr;21(1):76-81. 